\title{
Urban Sprawl and Its Financial Cost: - A Conceptual Framework
}

\author{
Shahriza bt Osman \\ Graduate Centre Department, Faculty of Architecture Planning and Surveying \\ University Technology MARA (UiTM) \\ 40450 Shah Alam, Malaysia: \\ Tel: 60-19-440-2925Ｅ-mail: shahriza@uum.edu.my \\ Abdul Hadi Nawawi (Corresponding author) \\ Graduate Centre Department, Faculty of Architecture, Planning \& Surveying \\ University Technology MARA (UiTM) \\ 40450 Shah Alam, Malaysia \\ Tel: 60-3-5521-1568 E-mail: abdulhadinawawi@yahoo.com \\ Jamalunlaili Abdullah \\ Graduate Centre Department, Faculty of Architecture, Planning \& Surveying \\ University Technology MARA (UiTM) \\ 40450 Shah Alam, Malaysia \\ Tel: 60-19-262-7100Ｅ-mail: jamal858@salam.uitm.edu.my
}

\begin{abstract}
Urban sprawl has been recognized as an urban expansion which leads to undesirable impacts in terms of sacrifice of farmland and loss of amenity benefits from open space on the urban fringe. Integral to the negative impacts of sprawl is the higher financial costs that have to be incurred mainly through expenses related to the physical development in an unplanned manner. A framework of understanding sprawl and its financial cost in a developing country's context namely Malaysia is proposed based on four (4) strategic steps namely, sprawl identification, measurement, decision and financial analysis utilizing the differential costs approach by comparing financial costs of development under unplanned sprawl and a planned strategy. The framework would provide a structured insight into quantifying the financial costs of sprawl to guide economists and urban planners in making a decision pertaining to urban development.
\end{abstract}

Keywords: Sprawl, Financial cost, Conceptual framework

\section{Introduction}

The phenomenon of urban sprawl has received extensive attention in the literature for the past fifty years. Empirical and geographical studies for over a decade have shown that sprawl development has detrimental effects on society and is costly. Factors influencing the development of sprawl are multifaceted and include rapid urbanization, agricultural, industrialization, migration, economic development, income growth, development policy, market failures and population growth. Concept of smart growth, balanced growth management, compact growth and sustainability all reflected the desire to balance between urban growth and protection of the environment. Thus the issue of sprawl is an issue of preference rather than an issue of necessity today. This is because three billion people live in cities and it is projected that by 2030, nearly sixty percent of the world population will be urban (Burchell, 2000). Classically, urban sprawl is a US phenomenon associated with the rapid low-density outward expansion of US cities, steaming back to the early part of the $20^{\text {th }}$ century. It was fuelled by the rapid growth of private car ownership and the preference for detached houses with gardens. It is clear that sprawl is associated with urbanization whether it takes place in developed or developing countries. Studies have shown that sprawl is more expensive than alternative patterns of development. The following costs are the direct result of sprawl, which include costs to taxpayers, social problems, high labor costs, new infrastructure, agriculture, car use and environment. In Malaysia, there is relatively low visibility of urban issues and there seemed to be many lingering problems which were the outcome of the urbanization process for the past thirty years. Thus, the first step in discussing the pertinent issue is to develop a framework for understanding the dimensions in financial cost of sprawl. This paper focuses on the conceptual framework on the financial costs of sprawl in Malaysia.

Urban growth follows a pattern of urban transition. The first phase is of fastest growth in the core of the city. The second phase is suburbanization with the fastest growth just outside the city core followed by the third phase that is 
counter urbanization, with population in the core and suburb moving out to more rural areas. The fourth phase is re-urbanization with an increase in population in the core of the city (Berry and Plaut, 1976). According to this model, the phenomenon of sprawl would fall into the third phase of urban growth. Studies have shown that sprawl is more expensive than alternative patterns of development. The following costs are the direct result of sprawl, which include costs to taxpayers, social problems, high labor costs, new infrastructure, agriculture, car use and environment.

Sprawl had varying definitions, and the central component of most definitions is low density, pattern of land use conversion which exceeds the population growth rate over a specified time period and the changes of the rural landscape of farmlands, parks and other natural areas into human-made environments. According to Beck and Kolankiewicz (2001), sprawl is a low density, large-lot residential and commercial development that is scattered across a large land area. This land area is separated into distinct zones requiring regular inter-zone travel. Burchell (1998) defines sprawl as a low density residential and non-residential intrusions into rural and developed areas and with less certainty such as leapfrog, segregated and land consuming in its typical form. Galster et al. (2000) define sprawl as a pattern of land use that exhibits some combination of dimensions including low density, discontinuity of development and little open space within the urban area. Residents of sprawling neighborhoods tend to live in single-family homes and commute by automobile to work. The context include human settlements spreading out in poorly planned patterns, occur in respond to population growth average number of residential units of developable land and land is developed at a faster rate than the population rate.

The most fundamental characteristic of sprawl is that it includes two sets of infrastructure being created that are underused. One is the cities and older developed suburbs (oldtown) and the other the new sprawling development (newtown).The following traits make it costly, low-density, automobile dependence, leapfrog development, street segregration of housing, loss of farmland, commercial development and fragmented planning and governance (Burchell, 1998). Its effects are impacting the quality of life in every large and small cities. Sprawl leaves behind boarded up houses, vacant storefronts, closed business, abandoned, contaminated industrial sites and traffic congestion. Sprawl also creates cost such as the hidden debt of unfounded infrastructure and services, social dysfunction, urban decay and environmental degradation. The list of costs is endless so there is a need for consistent methodology to quantify the total cost of sprawl development. Sprawling developments should reflect the true costs and impacts associated with those developments. There are a remarkable number of causes of sprawl which include demographic changes, growing affluence, rent gradient, transportation, land regulation and federal tax policy (Frank, 1989). Chesapeake Bay and Mid-Atlantic (2001) recognize sprawl development consist of three basic spatial characteristic such as low-density sprawl, ribbon and leapfrog development. Low-density sprawl is the consumptive use of land for urban purposes along the margins of existing metropolitan areas. This type of sprawl is supported by piecemeal extensions of basic urban infrastructures such as water, sewer, power, and roads. Ribbon sprawl is development that follows major transportation corridors outward from urban cores. Lands adjacent to corridors are developed, but those without direct access remain in rural uses. Over time these nearby "raw" lands maybe be converted to urban uses as land values increase and infrastructure is extended perpendicularly from the major roads and lines. Leapfrog development is a discontinuous pattern of urbanization, with patches of developed lands that are widely separated from each other and from the boundaries, albeit blurred in cases, of recognized urbanized areas. This form of development is the most costly with respect to providing urban services such as water and sewerage.

The following discussion is about the factors that lead to sprawl development process. Industrial Revolution is a process of social and economic change whereby a human group is transformed from a pre-industrial society (an economy where the amount of capital accumulated per capita is low) to an industrial one (a fully developed capitalist economy). In recent years, other countries like Mexico, Brazil or Turkey have experienced a moderate industrial growth, fuelled by exportations to bigger economies like United States, China or the European Union respectively. They are sometimes called newly-industrialised countries. In 2005, the USA was the largest producer of industrial output followed by Japan and China. With industrialization, there is social and economic change which is closely related to technological innovation development in production. Industrialisation also introduces some form of philosophical change, or to a different attitude in the perception of nature as well as jobs for more people.

Urbanization is a process where cities grow as people move from the countryside in search of better jobs and living conditions. The world's cities are growing because people are moving from rural areas in search of jobs, opportunities to improve their lives and create a better future for their children. . This trend of movement will continue for the next 30 years. Also, the ever increasing number of factories created an intense need for labor, convincing people in rural areas to move to the city, and drawing immigrants from Europe to the United States. As a result, the United States transformed from an agrarian to an urban nation, and the demographics of the country shifted dramatically. Malaysia was transformed from an agricultural country to manufacturing and industrial country by the 1980's.

Migration is already contributing to sprawl (Garling, 1999). Cromartie et al (1997) define migration as the displacement of a person who leaves their place of birth or of residence for another place. It is most often internal, with migrants 
remaining in their country. The migrant often leaves a rural area to live in an urban area, which fuels urbanization. International migrations are rare, with only three percent of humans living in a country other than the country in which they were born. As migration pour into already crowded urban areas, native Americans are pushed out into expanding exurbs and suburbs.

Economic well-being and quality of life for a community by creating and retaining jobs and supporting or growing incomes and the tax base when there is economic development. Burchfield et al (2006) also define economic development as a sustainable increase in living standards. It implies increased per capita income, better education and health as well as environmental protection. Economic development has evolved into a professional industry of highly specialized practitioners normally working in public-private partnerships that are sanctioned and many times at least partially funded by local, regional and state/provincial tax dollars. These economic development corporations function as individual entities and in some cases as departments of local governments. Their role is to seek out new economic opportunities and retain their existing business wealth. The measurement of success within this industry is normally job creation, economic growth and increased or retained tax base.

Income growth is a growth or increased of total amount of goods and services that a person receives, and thus there is not necessarily money or cash involved (TDM Encyclopedia, 2007). This may reveal the existence of politically unacceptable inequality of income. There may be strong political pressure to adopt policies of income redistribution by taxing the richer people at a higher rate than the middle class and giving subsidies or income-support to the very poor in a variety of ways. Political economy tends to be highly controversial because people have conflicting opinion regarding income redistribution. National income, measured by statistics such as the Net National Income (NNI), measures the total income of individuals, corporations, and government in the economy. The theoretical generalization to more than one period is a multi-period wealth and income constraint. Changing measured income and its relation to consumption over time might be modeled accordingly, such as in the permanent income hypothesis

Population growth is the main driving force of adverse impacts on the environment. Increase in the number of people in an area leads to higher pressures on the environment. More people need more space, require more energy, water, and natural resources, which inevitably leads to higher pressure on land, air, water, and natural resources. They also produce more waste, which again has an impact on land, waters, and air. Rising economy and industry also contribute to generating more pressure on the environment.

\section{Measurements for Sprawl}

It is necessary to have accurate and practical performance indicators for sprawl in monitoring the progress and costs of sprawl in order to achieve sustainable cities. These indicators are tools for identifying existence of sprawl in a locality. The widely used indicator is density which is expressed as the total number of population to its total land areas. Sprawl exists in low density development which is the consumptive use of land for urban purposes along the margins of existing metropolitan areas. This type of sprawl is supported by piecemeal extensions of basic urban infrastructures such as water, sewer, power and roads. The second indicator is land use change, which is leapfrog development. It is a discontinous pattern of urbanization with patches of developed lands that are widely separated from each other and from the boundaries. This form of development is most costly in terms of providing urban services such as water and sewage. Other indicators include loss of farmland, population growth, housing affordability, crime rates, employment and travel time. Indicators help to make adjustments and to adapt actions to rapid change, to fine tune policies to fit local conditions, to identify opportunities, to become creative about new possibilities.

Density is the most important dimension of sprawl. It is expressed as the total number of population to its total land areas (Black, 1996; Alberti, 1991 and Burchell et.al, 2005). Density is seen as both the average number of residential units per square mile of developable land in an urban area and the average number of people per square mile (Wendell and Utt, 2004). A metropolitan area that has more of its population that is concentrated appears less sprawled than one with a population that is evenly distributed across its region. RERC (1974) found that capital costs per unit were higher in the low-deversity sprawl and sprawl mix neighborhood prototypes than they were in the planned mix or high density planned mix prototypes. Burchell et al. (2005) found infrastructure costs were highest in situations of low density and for development located a considerable distance from centralized public services (conditions of sprawl). Thus, density of development was found to be inversely related to lane miles of local and state roads and their attendant infrastructure costs. Infrastructure costs were lowest in situations of higher density and for development that are centrally and or contiguously located (conditions of compact development). Duncan and Associates (1989) analyzed the infrastructure costs of multiple Florida residential and nonresidential developments with varying patterns of development. Costs were higher for those with sprawl characteristics than they were for those with compact development characteristic.

Sprawl is also known as a process in which the spread of development across the landscape far out-space population growth that create a population that is widely dispersed in low-density development, rigidly separated homes, shops and workplace, a network of roads marked by huge blocks and poor access and lack of well-defined, thriving activity centers such as downtowns and town centers (Knapp et al, 1999). Population growth is the most significant factor 
effecting urban sprawl in the Mid-Atlantic region. As population size increases, so does the amount of land required for residential and commercial needs. In the Chesapeake Basin alone, between the years 1950-1980, the percent of land used for residential and commercial purposes increased nearly 80 percent while population about 50 percent. Population growth are costly because it tend to providing infrastructure and municipal services in sprawl area. Studies in California and Florida have shown these extra costs to be on the order of $\$ 20,000$ per residential unit (Wassmer and Baass, 2004). Costs of services to different areas of a municipality are also influenced by location whether new development occurs in areas where existing facilities, namely schools, libraries, parks and police stations. Cities witnessing both rapid population growth and urban disinvestment at the same time can have situations where taxpayers are paying for new facilities while other facilities are being underutilized. Between 1970 and 1995, the number of public school students in Maine declined by 27,000 , yet the state spent more than $\$ 338$ million building new schools in fast growing population (Longman et al, 1998).

Sprawled land use patterns increase the amount of land developed per capita, which reduce the land left as greenspace (biologically active land such as farms, forest and wetlands near urban centres. Kusher (2001) using a land use activity at rural land to define sprawl as the spreading out of a city and its suburbs over more and more rural land at the periphery of an urban area involves the conversation of open space (rural land) into built-up and developed land over time. Sprawl uses land and public financial resources. Consumers become restricted in where and how to live as sprawl develops in an area. It is clear that sprawl is associated with urbanization whether it takes place in developed or developing countries. With decentralization and sprawl development, farmland is rapidly disappearing. A study by the American Farmland Trust (1992) has estimated that the U.S. is losing about 50 acres an hour to sprawling developments. If this trend continues, the Trust estimates that 13 percent of prime U.S. farmland could be redeveloped by 2050 (Longman et al, 1998).

Housing is another indicator to measure sprawl development. Normally, sprawl will makes consumers or people reduce their consumption of housing space, making new homes smaller and the variety of housing types. For example, according to Bolioli (2001) who refers to the Grow Smart Rhode Island 2000 report, with regards to residential housing and its effect on land use and the environment, 71 percent of all housing in Rhode Island was located in urban areas. Sprawl also increase in the housing construction outside of the urban areas. For example, in Rhode Island, data from the state, most of the construction took place in the non-urban areas or sprawling areas (Bolioli, 2001). In general, increases in single-family units are considered less desirable since multi-family units are economically more cost effective and conceivably utilize less space per person for housing (Sussman, 1977). The vast majority of people are not moving into the urban areas but instead moving into the non-urban areas that finally cause a sprawl development. Despite being almost fully developed, the urban areas have land that is capable of housing more people than current numbers. For example, in 1998, within the urban areas, there were 8,723 vacant residentials lots and 2,065 vacant commercial/industrial lots (Knapp et al, 1999). At a rate of four people per house that would over 34,000 more people in the cities and lessened demand for new construction in the outlying areas. Synder and Bird (1998) estimate that each $\$ 1,000$ of impact fees adds $\$ 315$ to the annual income household will need to purchase a home. This is because, market based strategies discourage sprawl development and encourage new downtown development to exacerbate housing affordability.

Much of the research on the sprawl at the metropolitan level has focused on transportation behavior, researcher have developed several other metropolitan measures that potentially influence travel behavior. Sprawl leads to increase in vehicle dependence, which has both social and private cost. In the U.S., with the decline in density, has come a greater reliance on automobile (Burchell, 1998). From 1970 to 1996, the mileage people drive has grown four times as fast as the population, and twice as fast as licensed drivers. The number of cars has also outgrown the population. The cost of owning a car can be a financial burden on families. Owning car and operating a car costs about $\$ 3600$ a year which translates to about 16 to 20 percent of total household expenditure (Young, 1995). Driving also has cost associated with lost of habitat, congestion, resources consumption and decline in air quality. The costs of the increased reliance on the automobile in the U.S. have been estimated to be as much as $\$ 184$ billion a year (Cobb, 1998), which does not even productivity losses from congestion or tax revenue losses from the land used for roads. Traffic congestion is also costly in terms of fuel loss and time loss. The average worker now spends about nine hours per week, or more than full working day, traveling in a car due to increased commuting times and congestion.

As some areas face a structural change from agricultural and industrialization and generally from the urbanization, it can develop the sprawl area. It is also when population size increases, the amount of land required for residential and commercial needs also increased. Migration, economic development and development of policy are other causes for sprawl. Sprawl is said to occur when the rate of land conversion and consumption for urban uses exceeds the rate of population growth area over a period of time. Frank et al (2000) identifies a combination of economic forces, social and technological change that have interacted to produce sprawl. Sprawl occurs in urban areas and it indicates pattern of land development in which the rate of land consumed far exceed the rate of population growth which results in an inefficient use of its associated resources. 


\section{The Financial Cost of Sprawl}

The term "cost" is defined as the resources expended relative to a type, density and location of development. It include physical, monetary, temporal, social and psychological resources (Burchell, 1998). They involve costs to the individual, community, society and the government and are documented overseas but none in Malaysia. Empirical data have shown that sprawl consumes thousands of acres of forest, farmland and wetland. It requires the government to spend millions extra to build new schools, streets, water and sewer lines. At the same time, sprawl leaves boarded up houses, vacant store-fronts, closed business abandoned often contaminated industrial sites and traffic congestion stretching miles from urban centers. As a result of sprawl, people suffer from increased traffic congestion, longer commutes, increased dependence on fossil fuels, crowded schools, worsening air, water pollution, increased floodings, destroyed wildlife habitat, higher taxes, loss of open space and dying city centers. It also creates a hidden debt of unfunded infrastructure and services. The list of costs is endless so there is a need for consistent methodology to quantify the total cost of sprawl development.

Extensive research over the past decades worldwide has shown that sprawl comes with a heavy price tag. Sprawl creates a never ending upward spiral costs. The most prominent researcher regarding sprawl is Burchell (1998), who provided quantitative data supporting the strong relationship between sprawl and increased private and public expenses. He published a comprehensive review, synthesis and its impact on two developments that is sprawl and controlled development. The analysis found that sprawl would result in $\$ 227$ billion in additional costs for sprawl versus controlled growth. Burchell (1998) found that US citizen in Los Angeles area pays $\$ 535$ billion to live in sprawl areas that is $\$ 430,465$ per person. Hence, sprawl is costly in terms of providing public infrastructure and services such as roads, garbage collection, and public transportation. Burchell et al (2005) found that sprawl increases local road lanes-miles by $10 \%$ annual public services and housing cost about $8 \%$. Burchell (1992) analysed the effect of implementing a managed growth strategy in the State of New Jersey in the form of a State Plan. Two alternative futures are modelled, one with development (TREND) and another with development according to the proposed State Development and Redevelopment Plan(PLAN). The study showed that the state could save $\$ 1.4$ billion in infrastructure funding over 20 years for roads, utilities and schools if it followed the PLAN versus the TREND scheme. The PLAN approach directed new growth to where excess capacity existed, rather than to virgin territories. On the other hand, PLAN more compact than the TREND, therefore requiring less distance to be covered when linking developments by local and country roads. Burchell (1998) using the same methodology found that population, jobs and households were increased both TREND and PLAN. It was found that PLAN would save cost. For example, the cost of \$699 million in roads can make a 24 percent saving.

Table 1 includes some of the findings of his study:

Besides the social costs associated with sprawl such as health (Cox and Utt, 2004), uncomfortable living conditions associated with global warming (TDM Encyclopedia, 2007), pollutant emissions from traffic jams (Burchfield et al, 2006), physical costs namely increased infrastructure costs associated with sprawling development compared to compact development has also been emphasized (Burchell et al, 2005, Wassmer and Bass, 2004). The largest single sector of the literature on costs and benefit of current development of sprawl is capital and operating costs, both public and private. Some of the studies had variability due to the nature, that is some studied existing development, others used the hypothetical, some studied specific geographical areas while others analyzed the country as a whole. Many of the studies measure a certain aspect of development costs, capital costs, operating costs and maintenance costs but no study can measure all the potential added costs of sprawl. There were studies that measure the costs to government and ignore the cost of privately provided services (Cox and Utt, 2004). One common ground on the studies on the cost of sprawl is that it is costly than smart growth. Studies consistently found that lower densities increase public and private sector costs. A fundamental characteristic of sprawl is that there are two sets of infrastructure. The dual cost is one providing new infrastructure for those moving outward and the second is maintaining the old infrastructure for the population and economic entities left behind. These costs include roads, sewage, water, garbage collection and maintenance.

Another issue is the additional cost to the local government which has an impact on the local economy, given the interdependency between the fiscal health of a community and its economic health (Ladd, 1998). Based on the logic of capital investment (Lyne,2002), the degree to which business are attracted to a locality depends on the ability of the local authorities to offer an optimal tax/service level that is lower taxes or, alternatively, better services for higher taxes. The presence of business in a locality generates growth cycle resulting in their contribution to the local tax-base. Increasing fiscal capacity helps localities reduce overall taxes, increase services or subsidize new businesses. If this is true, then the reverse is also true: sprawl can spur a cycle of economic decline and the "crowding out" of businesses. This occurs if sprawl produces a net-loss for the local government which, consequently, is forced to increase taxes in order to maintain the existing level of services.

Stephenson et al (2001) measures the cost of sprawl by looking at the total local government cost. The total government costs can be calculated by multiplying population served by the per capita costs to serve the population. The per capita 
cost of providing services can then be effected by the spatial attributes of development (as defined above), demographics and service standards. The local governments commonly provide a variety of services such as education, police protection, water, sewer, parks, roads and recreation. The diagram below (Figure 1), basically shows the relationship between local government costs and spatial arrangement of development.

A review on the cost of sprawl appears to warrant that sprawl is costly financially (Altshuler, 1977).. The municipalities in United States can no longer pay for the infrastructure necessary to develop farther and farther out in metropolitan areas. The benefits of smarter growth, but the actual cost of sprawl needs to be quantified. In discussing cost of sprawl, the benefits are also considered in terms of savings when comparison between two types of development is being carried out. So, before the financial cost of sprawl is being identified, measurement of current development patterns and the degree of sprawl is required using appropriate indicators.

\section{Urban Sprawl in Malaysia}

Malaysia is experiencing rapid urbanization which is a result of natural population growth and rural urban migration due to push and pull factors of social and economic conditions (Abdullah, 2003). In addition, sprawl is also the result of the moving of urban populations from major city centres to urban fringe areas due to changing lifestyle which emphasized on spacious and more comfortable and environmentally friendly living environment. With this trend continuing to happen; towns and cities in Malaysia will continue to grow and expand to accommodate the growing and complex demand of the people. Experiences have shown that rapid and uncontrolled expansion of towns and cities has led to amongst others the deterioration in the quality of urban environment and sprawling of urban development onto prime agricultural and forest areas as well as cities starting to lose their identity. In order to avoid such phenomena continuing to happen, particularly in the Kuala Lumpur Conurbation Area, towns and cities need to be properly planned and managed so that their growth or expansion can be controlled and managed in a sustainable manner. This will then hinder the land and property values and environmental quality to further decline and deteriorate. One of the strategies adopted to curb sprawling development is through the delineation of urban growth or development limits. This means that the limit of towns and cities need to be studied and identified, so that urban development can be directed to areas which are identified and specified suitable for such development (Shamsuddin and Yaakup, 2008). In such a manner, prime agricultural and forest areas as well as other environmentally sensitive area can be protected. It is hoped that such management tool can spur moderately to higher densities, eventually achieving a more efficient and livable communities. In order to justify the control of unplanned growth or sprawl, it is important to develop a conceptual framework of financial cost of sprawl in Malaysia to analyze the financial implications of sprawl compared to a more planned growth. The previous review of literature provides the foundation for a conceptual framework of sprawl and its financial cost. This will be discussed in the following sections.

\section{Conceptual Framework of Sprawl and its Financial Cost}

The conceptual framework of sprawl and its financial cost presented here includes four stages which lead to the determination of the financial cost of sprawl (Figure 2). The first stage is the identification of sprawl stage based on the definitions of sprawl as well as the cost of sprawl via literature reviews. The second stage focuses on the measurement indicators for sprawl which include density, land use, population growth, built-up area, housing and volume of traffic flow. Sprawl indicators are tools to measure urban conditions, changes and form the basic data for this research. The third and fourth stages concentrate on making decision whether to allow sprawl or to concentrate on planned development based on financial analysis in terms of differential costs between sprawl development and planned development. Urban physical services that form the basis of the costs analysis will be identified such as infrastructure which is the key to urban development. Among them are roads/highway, water, waste treatment, schools and residential use. The current as well as new infrastructure will be evaluated. The existing infrastructure affect current and future requirements through the repayment of existing principal and interest on any financing that was used to acquire the infrastructure. There are also cost associated with the use of the infrastructure such as power and labor. Other consideration is the ongoing maintenance and replacement costs. As for the new infrastructure, revenue requirement will include increase debt charges in future years to repay any financing, raising current revenues to finance the acquisition, incremental operating costs and maintenance costs. Assessment on the cost of providing the services will be included on-site, off-site, capital costs, development costs, operating cost, sunk cost and working capital. These analyses address the costs to be incurred by both the public and private sectors in terms of monetary costs. The measurement of cost is computed on a per capita, per housing unit and per land area basis. The financial analysis which includes the determination of the potential cost savings of planned development as compared to unplanned sprawl shall determine the financial viability of the projects. The major analytical tool of financial analysis of projects is the Discounted Cash Flow (DFC) technique. This technique translates the cash-flows extending into the future in terms of their present values. This method involves three steps which include preparation of the project cash-flow; discounting the net cash-flow and derivation of Net Present Value and Internal Rate of Return.

Financial costs are the value of all the net resources used or consumed to achieve specific organizational objectives. 
Economist sees costs as consequences of choices. But this paper will view the financial cost that is relevant to the development of sprawl, where a time period for analysis needs to be assumed. The financial cost is the differential costs which are sometime known as incremental cost. These costs are the dollar differences between the costs of alternative future actions that can be taken by the project program. A project is considered efficient when the maximum amount of output is produced from the given level of inputs. For example, a case for a decision on a project to build an apartment in a sprawl area compared to a single home residential project in a planned area using the discounted cash-flow analysis. A pilot case study using an apartment project in sprawl area in Penang, Malaysia is as follows.

Residential housing Project

Site area $\quad: 3.75$ acres

Density $\quad: 86.3$ per s.m.

Total No of Units: 480 units

Type of Unit

No of Units

\section{Percentage}

15 -storey apartment

(1 apartment obtain 120 units)

Total no of units (120 x 4)

4

480

1. Predevelopment Cost

Land cost@125,000 p.a x 3.75 acres

Conversion-Done

Land Survey 3.75 acres @ RM480

Soil Investigation

Plan fee 480 units (d) RM330

Title survey 480 units (d) RM300

Contribution to local authorities 480 units (d) RM800

Total

\section{Site Preparation and Infrastructure Works}

3.75 acres $x$ RM80, 000

\section{Building Cost}

Apattment 480 units (d) RM52, 000

Add $5 \%$ contingencies

Total

\section{Consultation Charges}

Layout plan 3.75 acres (d) RM380

Professional fees (d) 8\% of $2+3$ (RM28, 020,000)

Project Management Cost (Q) RM4,500 x 18 months

Reimbursable + out of pocket expenses

Total

\section{Other Expenses}

Landscaping 3.75 acres (d) RM1, 300

Sales Administration Advertisement

Interest charges, say $25 \%$ of RM31, 000, 00 at $9 \%$ p.a for 1

Year

Total

\section{Project Cost}

Predevelopment cost

Site preparation and infrastructure works $\underline{100 \%}$

RM

$469,750.00$

$1,800.00$

$7,950.00$

$158,400.00$

$144,000.00$

$\underline{1,164,900.00}$ $\underline{100 \%}$
$24,960,000.00$

$1,248,000.00$

26,208,025.00

$1,425.00$

$2,241,600.00$

$81,000.00$

$120,000.00$
$4,875.00$

$27,625.00$

$697,500.00$

$730,000.00$

$300,000.00$ 
Consultant charges

Building cost

Other expenses

Total

\section{Estimated Sales Income}

Apattment 480 units (d) RM85,900

\section{Return on Capital (Overall)}

$$
\text { Profit }=\text { RM41,232,000 }- \text { RM30, 847,300 }
$$$$
=\underline{\mathrm{RM} 10,384,700}
$$

Return on Capital $=\underline{\text { RM10 }}, 384,700$

$$
\begin{aligned}
& \text { RM30, 847,300 } \\
= & 0.3366 \\
= & \underline{33.66 \%}
\end{aligned}
$$

2,444,025.00

$26,208,000.00$

$730,000.00$

$30,646,950.00$

\section{$\underline{41,232,000.00}$}

Assumption on Financing of the Development

(1) $70 \%$ cost of the project cost is finance by the loan from financial institution and the rest of $30 \%$ is finance by own company's capital.

(2) Cost of the financing from financial institution is $9 \%$ p.a.

(3) Assume that we receive the loan in one lump sum at $\mathrm{T}=0$ and invest in saving deposit to gain a return of $8 \%$ p.a.

(4) Corporate tax is $27 \%$

(5) Cash from sales are receive $40 \%$ at $\mathrm{T}=3$, and $30 \%$ at $\mathrm{T}=9$ and $\mathrm{T}=15$.

(6) Administrative cost at $0.5 \%$ of sales and legal cost at $1 \%$ cost.

(7) Corporate required rate of return is $12 \%$ p.a. (1\% per month).

Differential cost analysis is being applied in comparing the financial costs of the project in the sprawl area and a residential project in a planned and this is shown in Table 2. The total development costs for the apartment project is RM 30,646,950 and initially it may appear that this is the amount if the project is carried out. However, in order to determine the actual amount of savings that will occur if an alternative planned development project is carried out, a comparison needs to be carried out for another planned residential project outside the sprawl area. The cost savings for the development of the planned residential project is RM 5,772,990 (RM 30,646,950 less RM 24,873,960).

The analysis will be applied to the various development projects' capital improvement resources such as infrastructure, transportation, capital, operating (assets) and also resource depletion cost.

\section{Conclusion}

This paper provides a conceptual framework for the evaluation of the financial cost of sprawl. It starts out from literature related the development of sprawl in a region and using tools for the measurement of sprawl. Measuring current development patterns and the degree of sprawl is the first challenge due to the varying definitions. But there are three principal characteristics, which include low density, leapfrog development and unlimited outward extension (Burchell, 1998). Sprawl is a type of growth where the future costs of sprawled area versus pursuing a more compact form of future growth. The financial costs are crucial issues because of the fact that such cost is often permanent, as the layout of infrastructure may inhibit infill development in the future. This is because the spatial dimensions of land-related services constitute an independent variable. The density of a development and its location, often lying outside the jurisdictional borders of a local policymaker, produce a financial impact. Once a subdivision is developed, the need for annual operating costs is irreversible. Moreover, these annual costs accumulate in tandem with the continuing development. As land is a nonrenewable resource, a bad land-use decision carries a double loss; the direct negative fiscal impact of a particular development, as well as the decreasing space for more beneficial development which could balance off such losses.

One of the most important mechanism used by local government to address the cost of sprawl are the application of impact fees to cover infrastructure and public services. Other tools being used are the smart growth program, urban growth boundary, zoning and excise taxes. The financial tools being used are site-value taxation, land value incremental taxes, tax increment financing districts, municipal fuel taxes. These mechanisms have both positive and negative implications, which affect a region's quality of life, lowered infrastructure costs, economic competitiveness, the state of the environment and sustainability. 
Rapid urbanization in Malaysia since independence fifty years ago, points to the need for urban growth management in order to achieve sustainability (Omar, 2003). The literature review confirmed that the context where sprawl exist is different and so are the patterns and if not check will lead to consequences socially, economically, environmentally and financially. It will also slow down the city development that will in turn slow other development pursuits. The ability to assess, measure and monitor sprawl depend on the availability of relevant, accurate reliable data. Much research needs to be carried out especially the financial cost of sprawl which had limited scholarly coverage till today. The potential application of financial costs of sprawl is the costs needed to be measured in terms of capital improvement but also resource depletion. According to urban theorists, there are two important prerequisites for continued city growth that is a solid economic base and density. So, if sprawl occur the result is that the core city area will lose out both their economic base and density. As a conclusion, sprawl is a man-made urban form that is costly to manage. Hence, a framework for managing sprawl in terms of understanding the associated financial costs is needed to enhance the decision making process in urban development projects.

\section{References}

Alberti, R. J. (1991). Geographic Information Systems : Applications For The Study Of Real Estate. Appraisal Journal, 60(4): 483-492

Altshuler, A. (1977). "Review of the Costs of Sprawl" Journal of the American Planning Association, 43(2): 207-209.

American Farmland Trust. (1992). Does Farmland Protection Pay? The Cost of Community Services in Three Massachusetts. Washington, DC: AFT.

Beck, R. \& Kolankiewicz, L. (2001). How Does Sprawl Threaten the Environment and Farmland? 1-2. USA.

Berry, D. \& Plaut, T. (1976). Effect Of Urbanization On Agricultural Activities. Growth and Change. 9, 3:2-8.

Black, J. T. (1996). The Economic of Sprawl. Urban Land. March, 55:3 pp. 52-53.

Bolioli, T. (2001). The Population Dynamics Behind Suburban Sprawl. Unpublished Ph.D Thesis, University of Rhode Island

Burchfield, M., Overman, H. G., Puga, D. \& Turner, M. A. (2006). Data From Causes Of Sprawl A Portrait From Space. Quartely Journal Of Economics, 121(2):587-633

Burchell, R. W. (1992). Impact Assessment of the New Jersey Interim State Development and Redevelopment Plan, Report II: Research Findings. Trenton: New Jersey Office of State Planning

Burchell, R. W. (1998). South Carolina Infrastructure Study: Projection of Statewide Infrastructure Cost, 1995-2015. New Brunswick, NJ: Center for Urban Policy Research, Rutgers University.

Burchell, R. (2000). The Cost of Sprawl Revisited. Rutgers University Press.

Burchell, R. W., Downs, A., McCann, B. \& Mukherji, S. (2005). Sprawl Costs: Economic Impacts of Uncheaked Development. Island Press. USA.

Chesapeake Bay and Mid-Atlantic (2001). Urban Sprawl: Forms of Sprawl. Towson University. $\mathrm{http} / / /$ chesapeake.towson.edu/landscape/urbansprawl/form.asp

Cobb, R. L. (1998). Government Policy and Urban Sprawl. Springfield, Illinois, U.S.A.

Cox, W. \& Utt, J. (2004). The Cost of Sprawl Reconsideration: What the Data Really Show. The Heritage Foundation Press.

Cromartie, John B. and Mark Nord. (1997). Effects of Intercounty Migration on County Per Capita

Income. Paper delivered at the 36th Annual Meeting of the Southern Regional Science Association,

Memphis, Tennessee, April 18, 1997.

Dasimah Omar. (2003). Urbanization, Urban fringe development and The Quality of Life:Evidence from New Town development in Peninsular Malaysia.paper presented at Adelaide Planning Congress 2003.

Duncan, J and Associates (1989). The Search for Efficient Urban Growth Patterns. A Study of the Fiscal Impacts of Development in Florida, U.S.A Working Paper.

Frank, J. E. (1989). The Cost of Alternative Development Pattern: A Review of the Literature. Washington, DC: Urban Land Institute.

Frank, N,, white, S., Peng, Z. R., Harris, K. and Sanders, W. (2000). Exploring Sprawl: Findings of a Comprehensive Review of the Literature Related to "Sprawl" or What Do We Really Know?. Paper Presented at the Association of Collegiate Schools of Planning, Atlanta, Georgia, November 2-5, 2000. 
Galster, G., Hanson, R., Ratcliffe, M. R., Wolman, H., Coleman, S. \& Freihage, J. (2001). Wrestling Sprawl to the Ground: Defining and Measuring an Elusive Concept. Housing Policy Debates. Vol 2, Issues 4.

Garling, S. (1999). Immigration and Urban Sprawl. Federation for American Immigration Reform Publications.

Jamalunlaili Abdullah. (2003). The Suburbanization of the Kuala Lumpur Metropolitan Region. Journal of the Malaysian Institute of Planners, 1:119-126.

Knapp, G. J., Yan Song., Ewing, R. \& Clifton, K. (1999). Seeing The Elephant : Multi-Disciplinary Measures Of Urban Sprawl. National Centre For Smart Growth Research and Education, University of Marryland.

Kusher,C.(2001). How is Sprawl Related to Landscape Change in Cities? http://www.sprawlcity.org

Ladd, H. (1998), Local Government tax and land use policies in the United states: understanding the links in W. Oates, ed, Studies in Fiscal federalism and State location. Cambridge, MA: Lincoln institute of Land policy.

Longman, W. Galster, H. G. and Harron, R. (1998). Wrestling Sprawl to the Ground. Urban Affair Review, Vol. 37, No. 5, pp. 728-744, New, York.

Lyne, J. (2002). Urban Sprawl : New Smart Growth America Study Moves To Measure Elusive Location Factor. The Side Selection Online Insider.

Real Estate Research Corporation (RERC). (1974). The Cost of Sprawl: Environment and Economic Costs of Alternative Residential Development Patterns at the Urban Fringe: (Volume I: Detailed Cost Analysis; Volume II: Literature Review and Bibliography). Washington, DC: U.S. Government Printing Office.

Shamsuddin, S. and Yaakup, A. (2008). Predicting and Simulating Future Landuse Pattern: A Case Study of Seremban district. Geospatial Application Papers. The Geospatial Resource Portal.

Stephenson. K. Cameron Speir, Shabman, L and Bosch, D. (2001) The Influence of residential Development Patterns on local Government costs and Revenues. Virginia Technology University publication, U.S.A.

Sussman, A. (1977). The Rights of Young People:- The Basic Aclu Guide to to a Young Person's Right. Ebay Publications.

Synder, K. \& Bird, L. (1998). Paying The Costs Of Sprawl: Using Fair-Share Costing To Control Sprawl. http:/www.smartcommunities/articles/sprawl.shtml

TDM Encyclopedia. (2007). Congestion Reduction Strategies: Identifying And Evaluating Strategies To Reduce Traffic Congestion. Victoria Transport Policy Institute.

Wassmer, R. W. \& Bass, M.C. (2004). Sprawl's Impact On Urban Housing Prices In The United State. Sacremento: California Senate Office Of Research.

Wendell, Cox and Utt, J. (2004), The Costs of Sprawl reconsidered: What data really show. The Heritage Foundation( www.heritage.org)

Young, D. (1995). Alternatives to Sprawl. Lincoln Institute of Land Policy, Cambridge.

Table 1. Savings from planned and compact growth

\begin{tabular}{|l|c|c|}
\hline Area of Impact & Savings:Lexington,KY,Delaware & Savings: State of Michigan \\
\hline Developable land & $24.5 \%$ & $15.5 \%$ \\
\hline Agriculture land & $29 \%$ & $17.4 \%$ \\
\hline Fragile land & $27 \%$ & $13.1 \%$ \\
\hline Infrastructure- roads & $19.7 \%$ & $12.4 \%$ \\
\hline Utilities-water/sewege & $8.2 \%$ & $13.7 \%$ \\
\hline Housing costs & $8.2 \%$ & $13.7 \%$ \\
\hline Fiscal Impacts & $6.95 \%$ & $3.5 \%$ \\
\hline
\end{tabular}

Source : Burchell (1998) 
Table 2. Cost comparison for two types of housing projects

\begin{tabular}{|l|c|c|c|}
\hline \multicolumn{1}{|c|}{ Cost item } & $\begin{array}{c}\text { Apartment } \\
\text { Under sprawl (RM) }\end{array}$ & $\begin{array}{c}\text { Single family home } \\
\text { Planned project (RM) }\end{array}$ & $\begin{array}{c}\text { Differential costs } \\
\text { (RM) }\end{array}$ \\
\hline Predevelopment Cost & $1,164,900$ & $1,050,400$ & 114,500 \\
\hline $\begin{array}{l}\text { Site Preparation and Infrastructur } \\
\text { Works }\end{array}$ & 300,000 & 150,000 & 150,000 \\
\hline Building Cost & $26,208,025$ & $22,113,560$ & $4,094,465$ \\
\hline Consultation Charges & $2,244,025$ & $1,010,000$ & $1,234,025$ \\
\hline Other Expenses & 730,000 & 550,000 & 180,000 \\
\hline Total Costs & $30,646,950,000$ & $24,873,960$ & $5,772,990$ \\
\hline
\end{tabular}

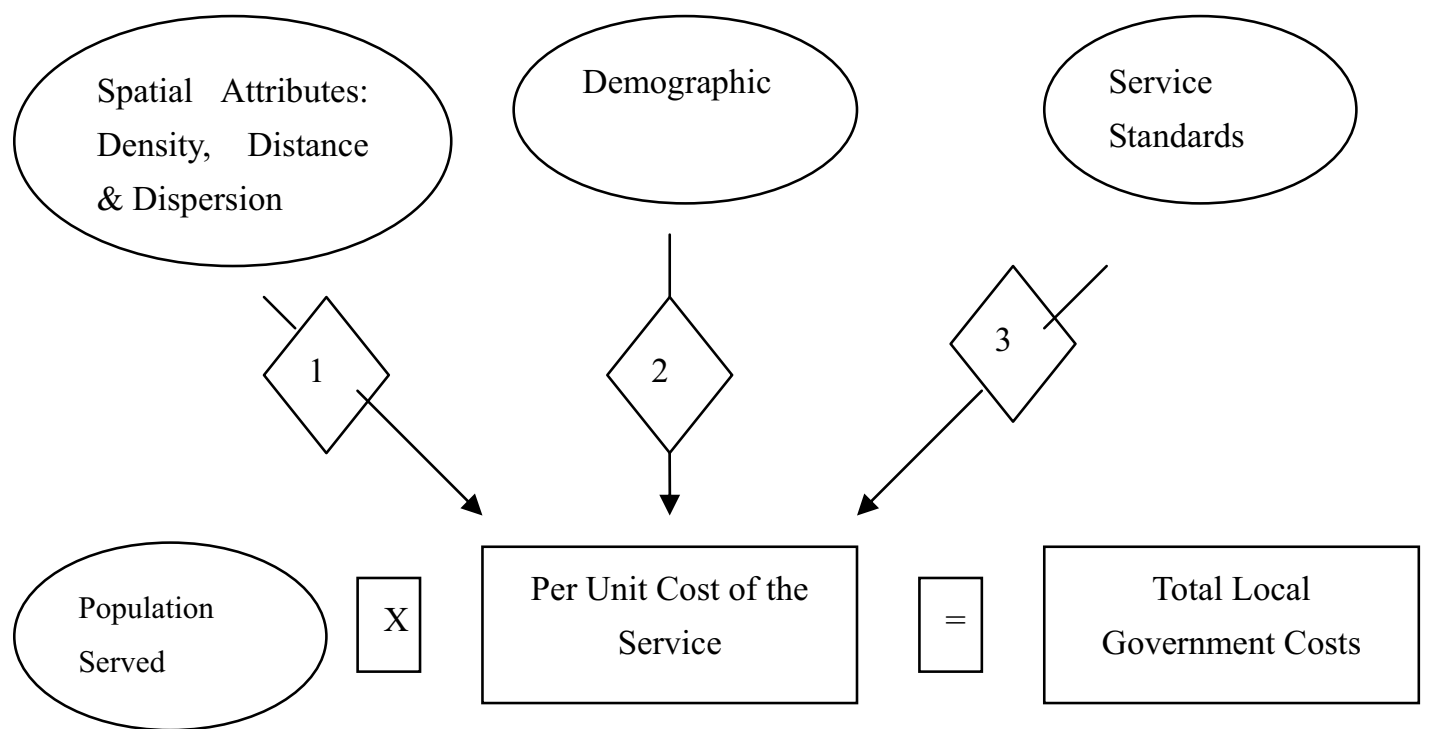

Figure 1. Direct Relationships between Local Government costs and Spatial Arrangement of Development.

Adopted from Stephenson et al (2001) 
Stage 1

Identification
Stage 2

Measurement

\section{Stage 3 \\ Decision \\ efficiency}

Stage 4

Financial-

analysis

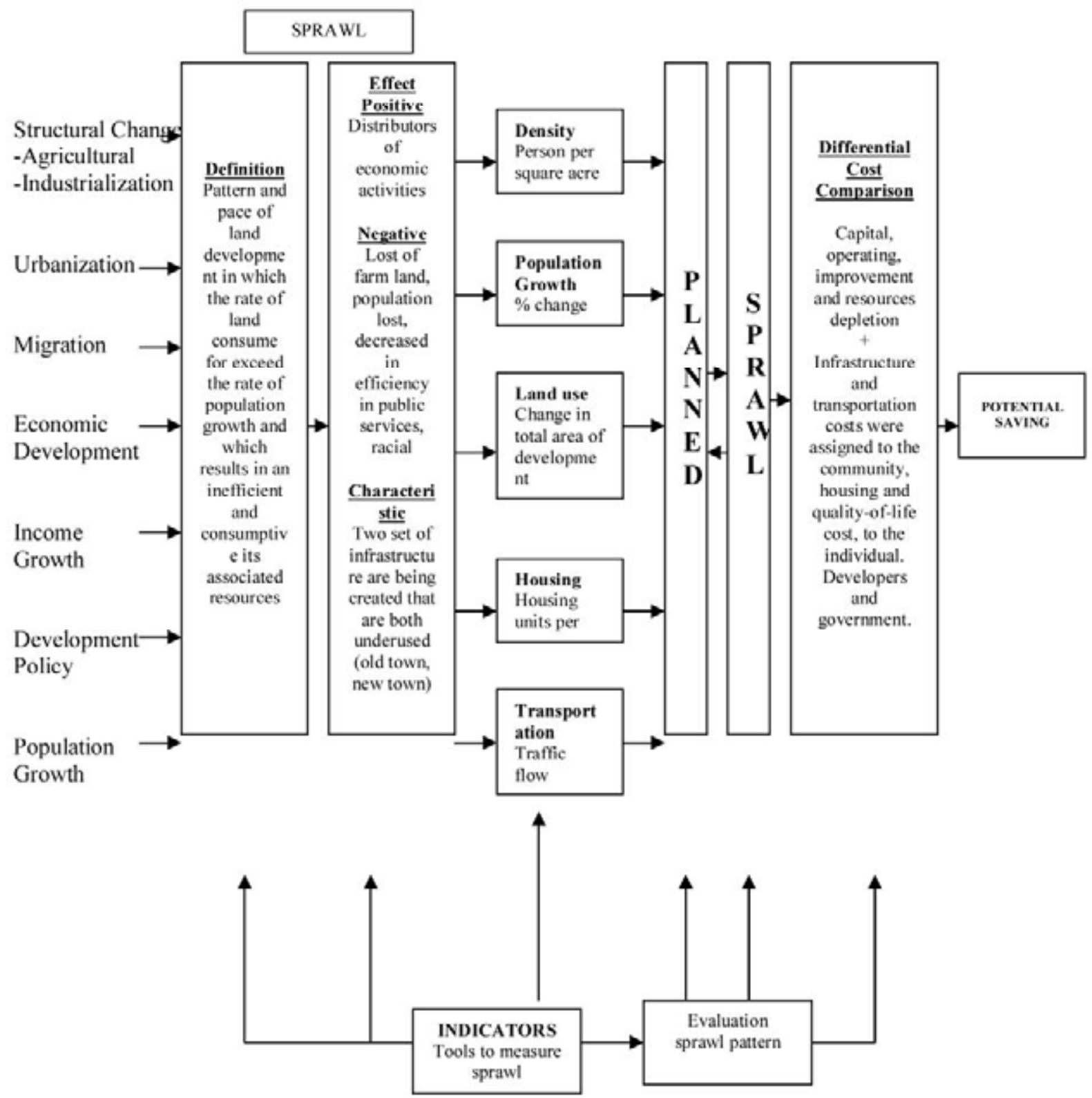

Figure 2. A Conceptual Framework of Financial Cost of Sprawl 